\title{
Influence analysis of changes of design parameters of passenger-car ferries on their selected sea-keeping qualities
}

\author{
Tomasz Cepowski, Assoc. Prof. \\ Szczecin Maritime University
}

\begin{abstract}
The main scientific aim of this research was to elaborate design guidelines which could make it possible to improve sea-keeping qualities of passenger-car ferries. The searchedfor design guidelines were prepared in the form of regression functions as well as artificial neural networks on the basis of the results obtained from calculations with the use of numerical methods based on the theory of planar flow around a body. The guidelines make it possible to predict ship roll, sea-sickness index, lateral and vertical accelerations on the basis of quantities available in the preliminary stage of ship design.
\end{abstract}

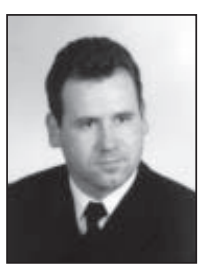

Keywords: passenger-car ferry, design guidelines, preliminary design stage, sea-keeping qualities, rolling, sea- sickness (motion-sickness) index, vertical accelerations, lateral accelerations, ship main dimensions

\section{INTRODUCTION}

Many dividing criteria of sea-going ships can be found because of variety of floating units, e.g. according to their functions, size, propulsion, architectural form, design problems, spatial subdivision etc. For most types of ships sea-keeping qualities are not an important design limitation. Exceptions from the rule are certain types of ships which can be divided into the following groups:

1. group of ships which have to fulfil their mission independent of weather conditions

2. group of ships characterized by design features which increase their susceptibility to weather conditions

3. group of ships intended for the carrying of passengers

4. group of transport ships for which sea-keeping qualities are only one of the limitations imposed on them.

The ships belonging to the groups have to be characterized by various sea-keeping qualities which can be modeled on different design levels (preliminary design - technical design). For each of the above mentioned ship groups important seakeeping qualities resulting from the functions to be fulfilled by them, can be formulated.

In this work only the group of passenger ships has been selected out of all the groups. The group can be further divided into:

1. ships intended for the carrying of passengers only:

- excursion ships (cruisers)

- passenger ships

- $\quad$ sanatorium and hospital ships

- yachts
2. ships intended for the carrying of passengers and general cargo:

- passenger -cargo ships

- passenger -cargo ferries: passenger-car ferries passenger-train ferries

- ropax ships

- passenger -container carriers.

The main design problems of ships of the group are first of all: their internal capacity, speed, and necessity of providing safety and comfort for passangers.

Among the first subgroup of the ships a. o. excursion ships (cruisers) are numbered. And, with a view of their large dimensions, to provide them with good sea-keeping qualities is not a problem. However for the remaining ships of the group, especially passenger ships intended for carrying caigo, design solutions are searched for to improve their sea-keeping qualities, such as these aimed at:

- the decreasing of roll motion which can cause cago to shift and in consequence to impair ship stability

the decreasing of accelerations which can cause lashing of fixed cargo to break (or cargo to shift)

- the moderating of accelerations which can generate seasickness

- the avoiding of parametric resonance of motion.

The passenger-car ship is a typical representative of the ships' group regarding the problems associated with the providing-for of appropriate sea-keeping qualities. 


\section{PROBLEM OF MODELING SEA-KEEPING QUALITIES OF PASSENGER-CAR FERRIES DURING PRELIMINARY DESIGN STAGE}

In ship design process design solutions which satisfy both economic criteria and technical limitations, are searched for . In the case of passenger -car ferry the economic criteria are consisted of many requirements put by shipowner, to which a.o. internal hull capacity or service speed can belongAnd, the technical limitations are formed from a.o. a group of factors affecting ship safety, i.e. first of all appropriate ship stability, unsinkability and hull strength.

Ship designers are often and often required to design some of the passenger-car ferries so as to additionally provide them, apart from general design merits, with immunity to weather conditions, i.e. good sea - keeping qualities.

Hull form and dimensions of a ferry are to a great extent decisive of its sae-keeping qualities. Therefore they should be modelled already in the preliminary design stageAn important feature of preliminary ship design is that exact form of ship hull is represented by means of the so-called main dimensions and global coefficients which characterize hull form, e.g. hull block, midship-section and vertical prismatic coefficients. The scarce set of information makes using the known methods of determination ship motions in waves, based on the classical linear or non-linear ship motion theory, not possible; hence in present it is important problem how to take fully into account the entire range of sea-keeping qualities already in the preliminary ship design stage. And, another problem is that the selection of improper values of ship main dimensions and hull form coefficients irreversibly worthens sea-keeping qualities (and other design merits as well) since any change of any dimensions of a ship after its building is economically unjustified.

Therefore this work has been aimed at the elaborating of design guidelines focused on improvement of sea-keeping qualities of sea-going passenger -car ferry already in the preliminary stage of its design.

\section{METHOD OF INVESTIGATIONS}

To reach the aim of this research the method consisted of the following phases, has been selected:

1. elaboration of a list of ferry-ships covering a broad range of their forms and dimensions

2. elaboration of operational scenarios important from the point of view of ferry operation and significantly affecting certain technical features of such ships

3. simplification of physical model by:

a. replacement of real weather conditions by statistical ones

b. replacement of real waves by a standard wave ener gy spectral density function

c. replacement of instantaneous ship response values by conventional statistical ones.

4. elaboration of symbolic mathematical model which describes the ferry design parameters $\mathrm{X}, \mathrm{X}_{2}, \ldots \mathrm{X}$, as well as the sea-keeping qualities $\mathrm{K}$ important from the point of view of an assumed ferry operational scenario

5. use of the exact numerical methods to calculate values of the parameter $\mathrm{K}$

6. selection of approximating functions for a set of discrete values of K-parameter, and elaboration of design guidelines with taking into account the parameter in question

7. assessment of the elaborated design guidelines

8. determination of a range of application and limitation of the elaborated formulas.

The detailed research algorithm is presented in Fig. 1.

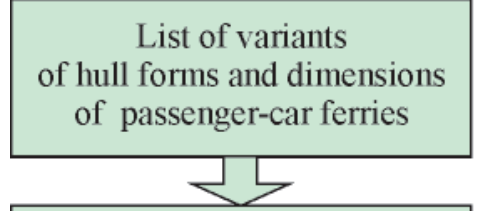

Calculation of K-paramter model values by using the exact methods

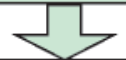

Analysis of the results and determination

of the parameters $\mathrm{X}_{1}, \mathrm{X}_{2}, \ldots \mathrm{X}_{\mathrm{n}}$ which significantly

influence the parameter $\mathrm{K}$

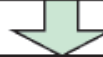

Elaboration of design guidelines

Fig. 1. Algorithm of the applied research method, where: $X_{1}, X_{2} \ldots X_{n}-$ ship design parameters, $K$ - a parameter which describes ship sea-keeping qualities

\section{LIST OF VARIANTS OF HULL FORMS AND DIMENSIONS OF PASSENGER-CAR FERRIES}

While elaborating the list of variants of hull forms of passenger-car ferries the recommendations contained in the report [4] were taken into account. In this research the list of 3072 variants was prepared by using a combination of the following items:

Tab. 1. Variants of passenger-car ferry hull form

\begin{tabular}{|c|c|c|c|c|c|c|c|c|c|}
\hline Variant & $\begin{array}{c}\text { CB } \\
{[-]}\end{array}$ & $\begin{array}{c}\text { CB(Lpp) } \\
{[-]}\end{array}$ & $\begin{array}{c}\text { CB(L) } \\
{[-]}\end{array}$ & $\begin{array}{c}\text { CB(V) } \\
{[-]}\end{array}$ & $\begin{array}{c}\text { CWL } \\
{[-]}\end{array}$ & $\begin{array}{c}\text { CWL(Lpp) } \\
{[-]}\end{array}$ & $\begin{array}{c}\text { CM } \\
{[-]}\end{array}$ & $\begin{array}{c}\text { XB/Lpp } \\
{[\%]}\end{array}$ & $\begin{array}{c}\text { XF/Lpp } \\
{[\%]}\end{array}$ \\
\hline 1 & 0.557 & 0.597 & 0.618 & 0.740 & 0.752 & 0.807 & 0.965 & 48.60 & 42.83 \\
\hline 2 & 0.642 & 0.642 & 0.657 & 0.777 & 0.826 & 0.826 & 0.977 & 48.79 & 44.44 \\
\hline 3 & 0.614 & 0.635 & 0.645 & 0.786 & 0.781 & 0.808 & 0.984 & 48.11 & 45.44 \\
\hline 4 & 0.614 & 0.614 & 0.638 & 0.743 & 0.826 & 0.826 & 0.963 & 48.00 & 45.34 \\
\hline 5 & 0.618 & 0.618 & 0.647 & 0.762 & 0.811 & 0.811 & 0.955 & 47.24 & 45.64 \\
\hline 6 & 0.629 & 0.629 & 0.657 & 0.743 & 0.847 & 0.847 & 0.958 & 46.62 & 45.04 \\
\hline 7 & 0.585 & 0.623 & 0.642 & 0.734 & 0.797 & 0.849 & 0.971 & 47.16 & 43.59 \\
\hline 8 & 0.609 & 0.609 & 0.639 & 0.759 & 0.803 & 0.803 & 0.954 & 47.61 & 46.00 \\
\hline
\end{tabular}

CB - block coefficient of underwater ship hull part, $\mathbf{C B}(\mathbf{L p p})$ - block coefficient of underwater ship hull part related to ship length between perpendiculars, $\mathbf{C M}$ - midship section coeffcient, $\mathbf{C B}(\mathbf{L})$ - cylindrical coefficient of underwater ship hull part, $\mathbf{C B}(\mathbf{V})$ - vertical prismatic coefficient of underwater ship hull part, CWL - waterplane coefficient, $\mathbf{C W L ( L p p ) ~ - ~ w a t e r p l a n e ~ c o e f f i c i e n t ~ r e l a t e d ~ t o ~ s h i p ~ l e n g t h ~ b e t w e e n ~ p e r p e n d i c u l a r s , ~} \mathbf{X F}$ - distance between geometrical centre of waterplane and aft perpendicular, XB - distance between centre of buoyancy and aft perpendicular, Lpp - ship length between perpendiculars 
a) the ranges of ferry dimensions:

- $\mathrm{LBd}=19$ 000, $28000,37000,46000 \mathrm{~m}^{3}$ (where: $\mathrm{L}$ - waterline length, $\mathrm{B}$ - waterline breadth, $\mathrm{d}$ - ship draught)

- $\mathrm{L} / \mathrm{B}=5.8,6.6,7.4,8.2$

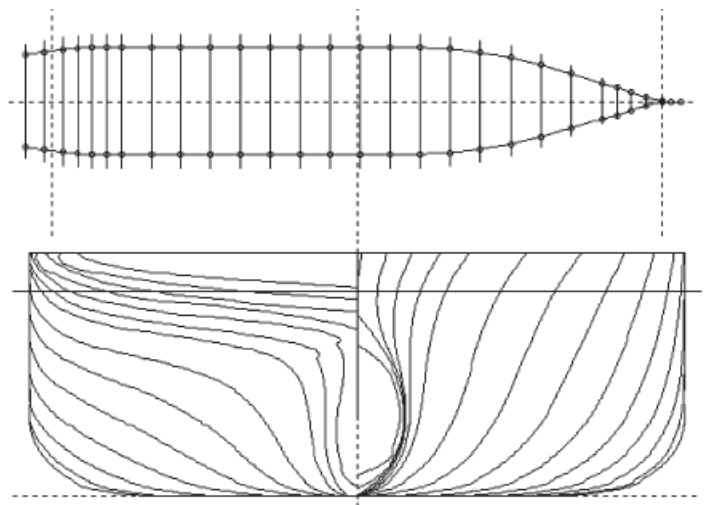

Variant 1

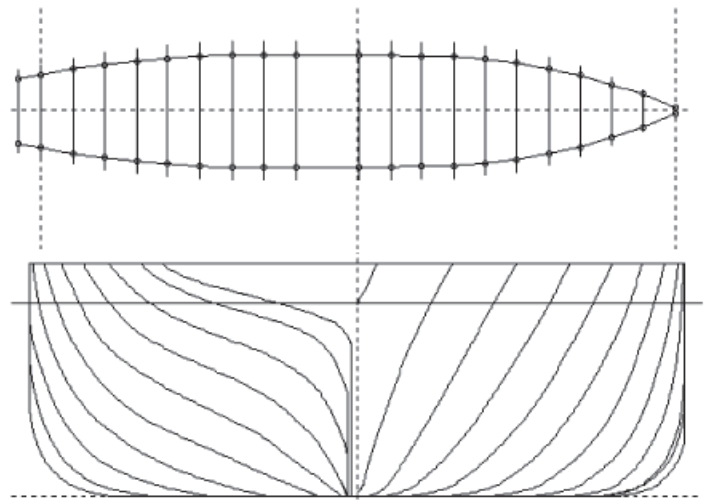

Variant 3

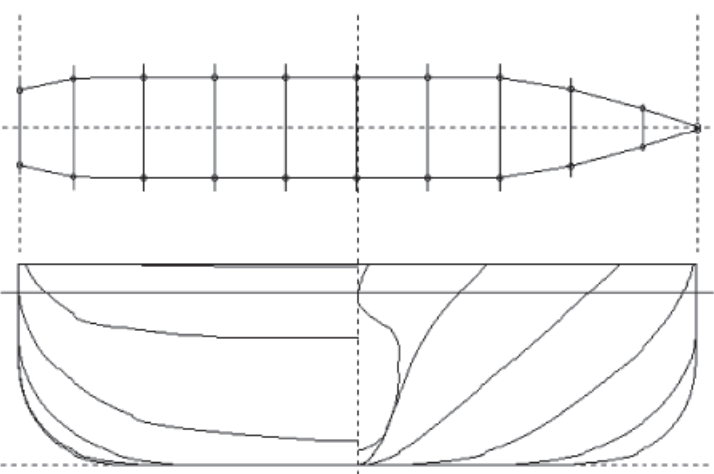

Variant 5
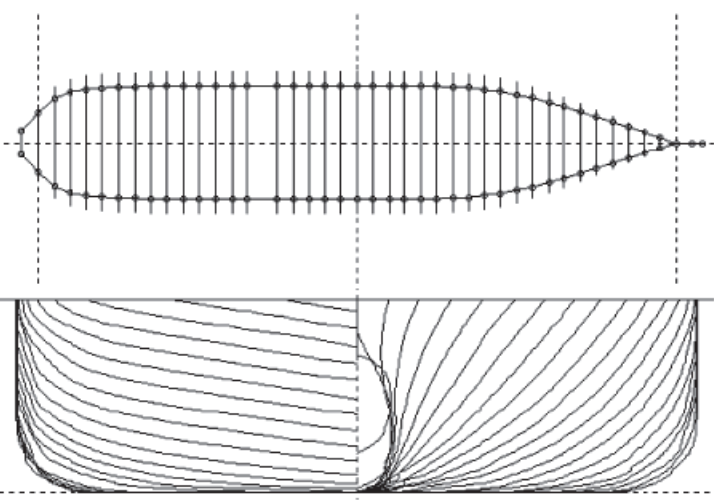

Variant 7
- $\mathrm{B} / \mathrm{d}=3,3.5,4,4.5$

b) the set of eight hull form variants (Fig. 2), represented by the global hull form coefficients contained in Tab. 1

c) the values of the initial transverse metacentric height GM, ranging from $0.4 \mathrm{~m}$ to $1.4 \mathrm{~m}$ every $0.2 \mathrm{~m}$.

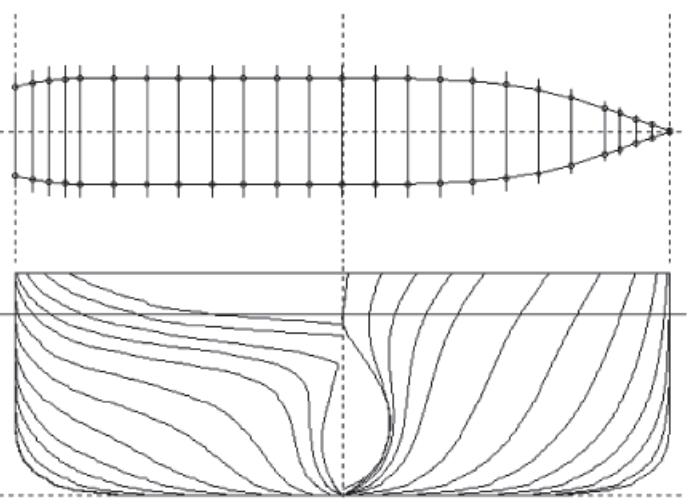

Variant 2

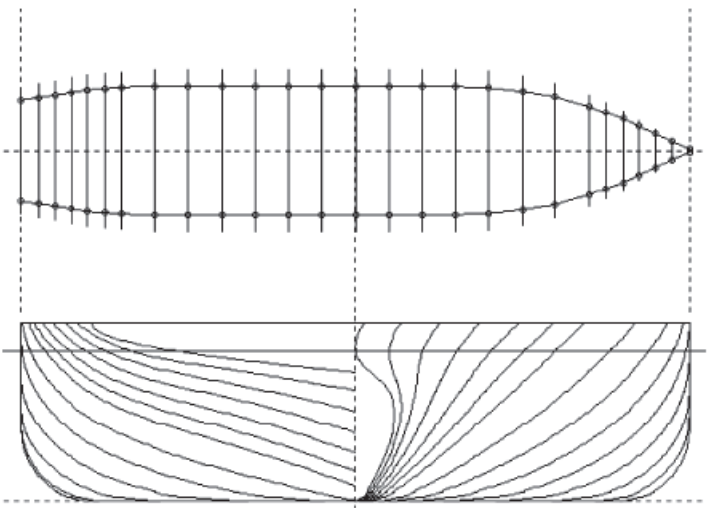

Variant 4
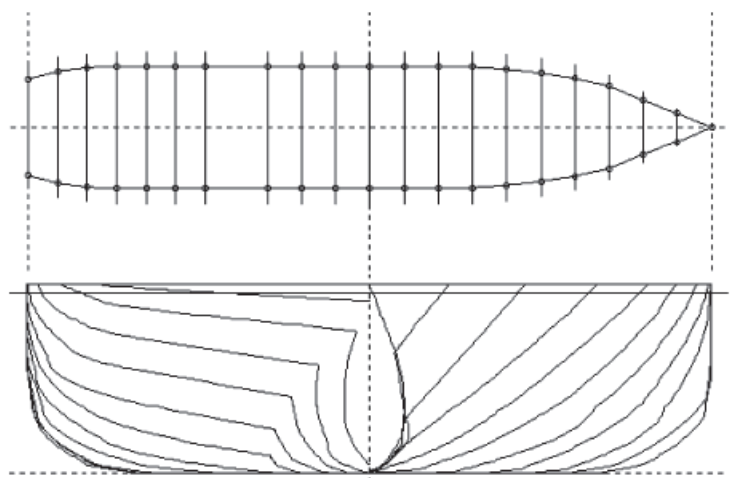

Variant 6

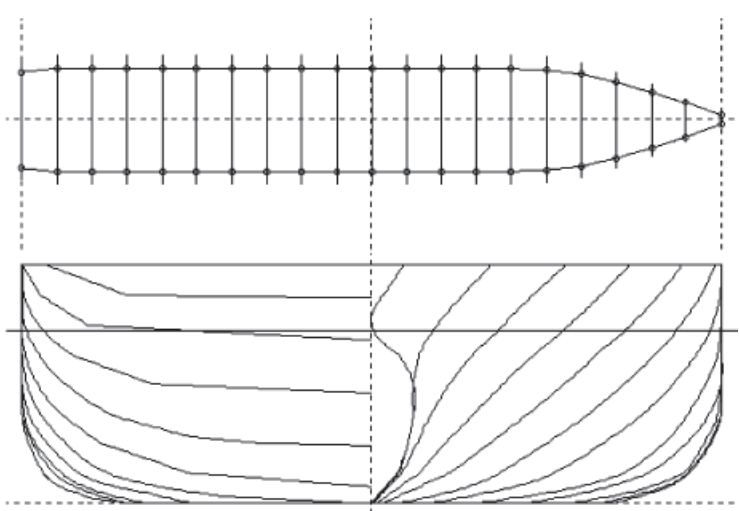

Variant 8

Fig. 2. Hull forms of passenger-car ferries, used in the research in question 


\section{OPERATIONAL SCENARIOS}

In the research it was assumed that the design guidelines will be elaborated for ferries operating in conventional service conditions. It was the conditions important from the point of view of its operational merits, in which a ferry could operate. Such approach has been based on the tar get assignment concept recommended by IMO Maritime Safety Committee for the elaborating of new assessment standards of ship stability [5].

Ship sea-keeping qualities are significantly infuenced by a.o. wave parameters, ship motion parameters (ship speed and wave encounter angle) as well as hydrodynamic ship hull parameters dependent on a form of its underwater part and weight distribution. For instance in Fig. 3 is presented impact of the characteristic wave frequency on statistically significant roll amplitudes of a ship, depending on varying values of initial transverse metacentric height of the ship moving with steady parameters of its motion.

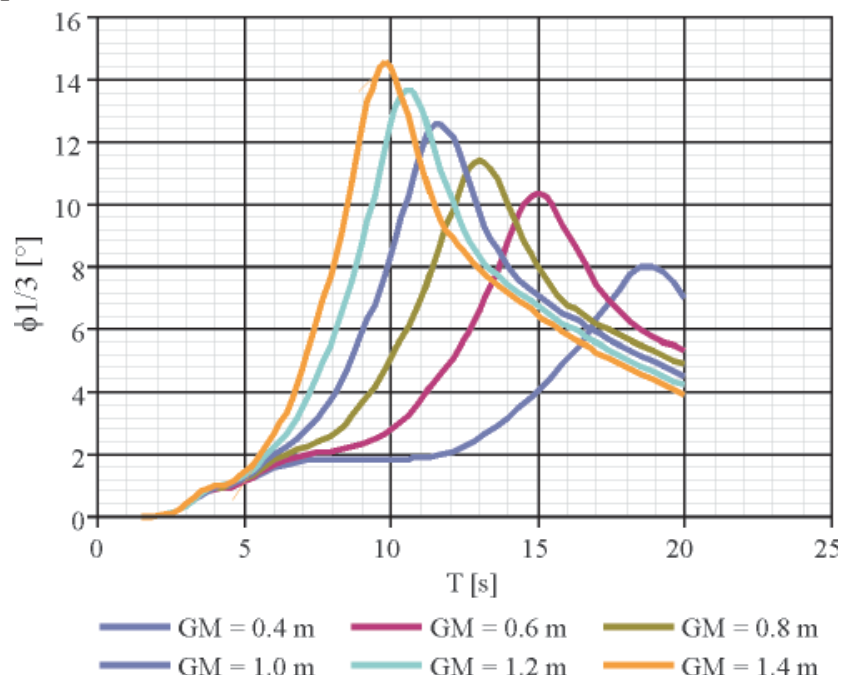

Fig. 3. Significant ship roll amplitudes in function of the characteristic wave frequency T, and: $G M=v a r, H s=3 \mathrm{~m}, \beta=60^{\circ}$ (where: $0^{\circ}$ - head wave,

$$
180^{\circ}-\text { aft wave), } v=0 \mathrm{~m} / \mathrm{s}
$$

As results from Fig. 3, the characteristic wave frequency together with the initial transverse metacentric height greatly influence ship rolling motion. From the point of view of design problems it is difficult to determine waving conditions in which a given ship operates, and especially troublesome to determine the characteristic wave frequency.

Therefore only such values of the characteristic wave frequency which generate maximum values of the considered sea-keeping qualities, were taken into account in order to eliminate influence of their impact on ship's behaviour.

In Fig. 4 for instance, is presented the relation between the initial transverse metacentric height and significant ship roll amplitudes for:

- a given value of the characteristic wave frequency (series 1)

- varying values of the characteristic wave frequency, in which significant ship roll amplitudes reach their maxima (series 2).

As results from Fig. 4, the series 2 show another trend and higher values of statistical ship rolling than the series 1 . Hence it results that the series 2 show influence of the initial transverse metacentric height on rolling motion of ship sailing in waves of the most unfavourable characteristic frequency.

With a view of the above mentioned aspects the following conventional operational scenarios were taken into account:

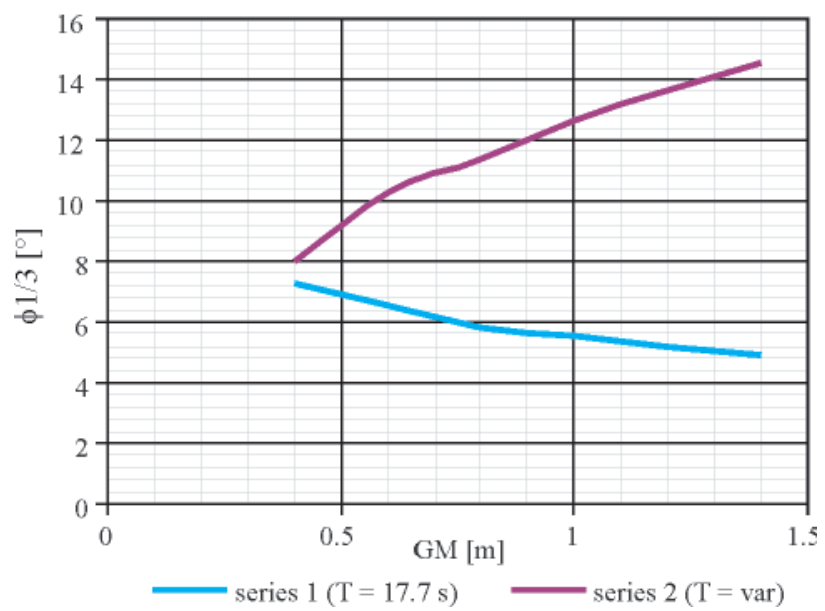

Fig. 4. Significant ship roll amplitudes in function of the initial transverse metacentric height GM: series 1 - for the characteristic wave frequency $T=17 \mathrm{~s}$, series 2 - for the characteristic wave frequency $T$ for which maximum ship roll values occur, $H s=3 \mathrm{~m}, \beta=60^{\circ}, v=0 \mathrm{~m} / \mathrm{s}$

1. the ferry has lost its propulsion ( found itself in waving conditions in which dangerous values of its rolling motion occur:

a. the ferry is obliquely situated relative to the incoming wave, that results in occurrence of maximum values of its rolling motion

b. the wave is of the characteristic frequency which produces maximum values of ship rolling motion

c. the significant wave height $\mathrm{Hs}$ is contained within the range of $1 \div 3 \mathrm{~m}$.

2. the ferry sails with the service speed $=12.5 \mathrm{~m} / \mathrm{s}$ in waving conditions which intensify occurrence of sea-sickness among crew members and passengers:

a. the ferry is obliquely situated respective to the incoming wave, that results in occurrence of maximum values of the sea-sickness index

b. the wave is of the characteristic frequency which produces maximum values of the sea-sickness index

c. the significant wave height $\mathrm{Hs}$ is contained within the range of $1 \div 3 \mathrm{~m}$.

3. the ferry sails with the service speed $V=12.5 \mathrm{~m} / \mathrm{s}$ in waving conditions which generate lage vertical and lateral accelerations in the point $\mathrm{P}$ (Fig. 5), which could cause trailers placed on car deck to shift [8]:

a. the ferry is situated at the angle against incoming wave, most unfavourable from the point of view of vertical and lateral accelerations

b. the wave is of the characteristic frequency which produces maximum values of vertical and lateral accelerations

c. the significant wave height $\mathrm{Hs}$ is contained within the range of $1 \div 3 \mathrm{~m}$.

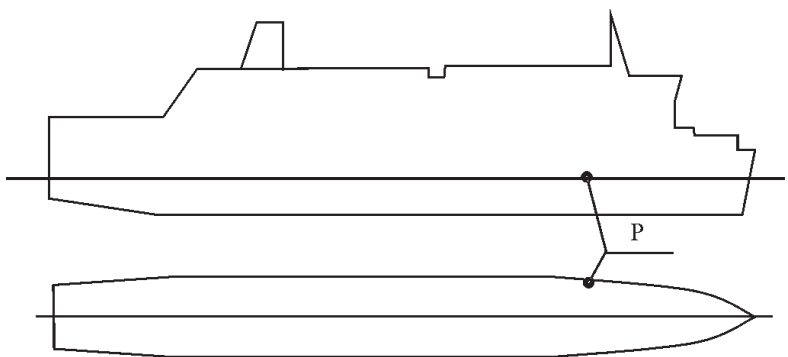

Fig. 5. The coordinates of the point $P$ located on the car deck, $(0.75 \mathrm{Lpp}$, $0.45 \mathrm{~B}, d)$, for which vertical and lateral accelerations were calculated, where: Lpp - ship length between perpendiculars, $B$ - ship breadth, $d$-ship draught 


\section{NUMERICAL CALCULATIONS}

For every variant of the passenger -car ferry sailing in the assumed operational conditions the following sea-keeping qualities (the parameter K, acc. Fig. 1), were calculated;

1. the maximum values of the significant statistical ship roll amplitudes, $\phi_{1 / 3 \max }$

2. the maximum significant values of the sea (motion) sickness index, MSI ${ }_{\max }$ (acc. [6])

3. the maximum values of the significant amplitudes of vertical accelerations, $\mathrm{a}_{\mathrm{vmax}}$, and lateral ones, $\mathrm{a}_{\text {tmax }}$, in the point $\mathrm{P}$, acc. Fig. 3.

For calculations of ship motion in statistical waves the JONSWAP wave spectrum was assumed to be a wave energy spectral density function. The calculations were performed by using the numerical methods of the SEAWAY software, based on the theory of planar flow around a body The method given in [3] was used for calculations of hydrodynamic coefficients. The accuracy tests of the SEAWAY software presented in [2], show a high accuracy of calculations carried out with the use of the program in question.

\section{SELECTION OF APPROXIMATING FUNCTIONS}

This research phase was aimed at elaboration of simplified analytical relations suitable for predicting selected sea-keeping qualities on the basis of ship design parameters.
To preliminarily identify the parameters which significantly impact the assumed sea-keeping qualities, the subject-matter literature, analysis of parameter influence on particular seakeeping qualities, as well as sensitiveness analysis was used by applying artificial neural networks. Next, the parameters characterized by the following features, were selected:

1. suitably high variability

2. strong correlation relative to dependent variable

3. weak correletion relative to the remaining independent variables of considered model

4. availability in preliminary ship design stage.

The selection of the approximating function was performed by verifying first the simplest linear functions. In the case when the verifying hypothesis was erroneous, non-linear functions (power, exponential, rational ones, etc), as well as functions represented by artificial neural networks which reveal the highest accuracy of approximation and the lowest dispersion, were searched for.

The approximation accuracy was assessed by using Pearson correlation coeffcient, and the dispersion - by means of standard deviation of error.

\section{DESIGN GUIDELINES}

The performed research resulted in the elaboration of the design guidelines presented in the form of the following relations (1), (2), (3), (4) and (5):

$$
\begin{gathered}
\phi_{1 / 3 \max }=\mathrm{H}_{\mathrm{S}} \cdot \frac{\left(\frac{1}{\left.1+\mathrm{e}^{-\left([0.072 \cdot \mathrm{B}-1.378,11.373 \cdot \mathrm{CB}-6.532, \mathrm{GM}-0.4] \times \mathrm{A}_{1}-\mathrm{A}_{2}\right)} \times \mathrm{A}_{3}-3.3488\right)+0.059}\right.}{0.0218} \\
\phi_{1 / 3 \max }=\mathrm{H}_{\mathrm{S}} \cdot\left(1.6221+\frac{2.5695}{\mathrm{CB}}-0.0997 \cdot \frac{\mathrm{B}}{\sqrt{\mathrm{GM}}}\right) \\
\mathrm{MSI}_{\max }=97287997 \cdot\left(\frac{\exp \left(\mathrm{H}_{\mathrm{S}}\right)}{\mathrm{FW}}\right)^{3} \\
\mathrm{av}_{1 / 3 \max }=36.57 \cdot \frac{\mathrm{H}_{\mathrm{S}}}{\sqrt{\mathrm{FW}}} \\
\mathrm{at}_{1 / 3 \max }=\mathrm{H}_{\mathrm{S}} \cdot \frac{1}{\left.1+\mathrm{e}^{-\left([0.007 \cdot \mathrm{LWL}-929,0.072 \mathrm{~B}-1.378,0.017 \cdot \mathrm{KF}-0.926,32.787 \cdot \mathrm{CM}-31.269, \mathrm{GM}-0.4 .4] \times \mathrm{A}_{4}-\mathrm{A}_{5}\right)} \times \mathrm{A}_{6}-1.107\right)+0.066} \\
0.059
\end{gathered}
$$

where:

$\phi_{1 / 3 \max }-$ significant roll amplitude (maximum value) $\left[^{\circ}\right]$

MSI $_{\max }^{1 / 3 \max }-$ Motion Sickness (sea-sickness)

Index (maximum value) [\%]

$\mathrm{av}_{1 / 3 \max }-$ significant amplitude of vertical accelerations (its maximum value) $\left[^{\circ}\right]$

$\mathrm{at}_{1 / 3 \max }$ - significant amplitude of lateral accelerations

(its maximum value) $\left[^{\circ}\right]$

B - $\quad$ ship breadth [m]

CB - block coefficient of underwater part of ship hull [-]

CM - midship section coeffcient [-]

GM - initial transverse metacentric height [m]

FW - waterplane surface area [m]

LWL - waterline length [m]
XF - distance between geometric centre of waterplane and its aft end [m]

$\mathrm{H}_{\mathrm{s}} \quad$ - significant wave height $[\mathrm{m}]$

$A_{1}$ - matrix of weight values:

$\left[\begin{array}{cccc}-8.2648 & -4.4049 & 2.6160 & 0.9067 \\ 0.7385 & 0.6195 & 1.2891 & -0.4663 \\ -13.5773 & -7.7457 & -0.0425 & 1.7976\end{array}\right]$

$\mathrm{A}_{2}$ - vector of threshold values:

$\left[\begin{array}{llll}-8.2648 & -4.4049 & 2.6160 & 0.9067\end{array}\right]$

$\mathrm{A}_{3}-$ column vector of weight values:

[-3.2109 $5.8162-1.74075 .4637]$ 
$\mathrm{A}_{4}-$ matrix of weight values:

$\left[\begin{array}{ccccc}1.244 & 0.400 & 1.205 & -0.763 & -1.714 \\ -3.021 & -0.137 & 3.079 & -4.673 & -0.040 \\ -2.501 & -0.516 & 0.898 & -2.687 & 1.653 \\ -0.416 & 7.030 & -0.718 & 0.707 & 5.162 \\ -3.699 & -0.436 & -3.545 & 4.176 & -0.364\end{array}\right]$

$\mathrm{A}_{5}$ - vector of threshold values:

[1.610 4.976 $0.700-2.9824 .313]$

$\mathrm{A}_{6}$ - column vector of weight values:

[2.141 2.494 $1.4931 .221-3.467]$

The relations (1) and (5) are in the form of MLP artificial neural networks whose structures are shown in Fig. 6. a)

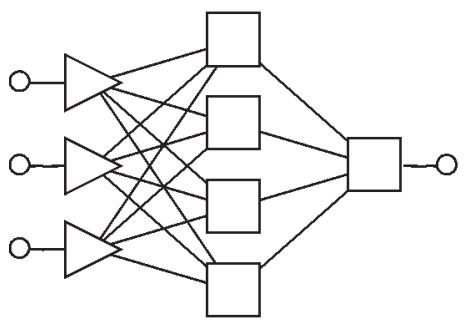

b)

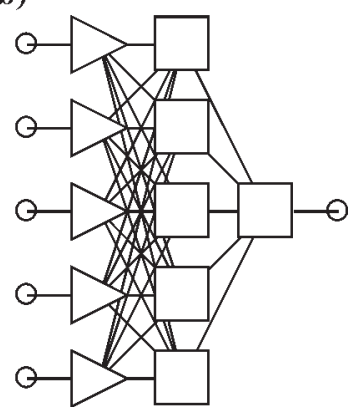

Fig. 6. Structures of MLP artificial neural networks used to approximate: a) significant roll amplitudes (maximum values), by inputs: $C B, G M, B$,

b) significant amplitudes of lateral accelerations (maximum values), by inputs: $L W L, B, X F, C M, G M$

\section{ASSESSMENT OF THE ELABORATED DESIGN GUIDELINES}

As results from Tab. 2, the relations (1), (2), (3), (4) and (5) are characterized by relatively high accuracy of approximation and low dispersion. The diagrams of Fig. 7 through 20 show comparison of accuracy of the formulas relative to their model values, as well as influence of the independent variables on approximation of the dependent variables. As results from Tab. 2 and the above mentioned diagrams all the relations are characterized by high correlation and low dispersion. Especially the relations (1) and (4) are characterized by high accuracy of approximation.

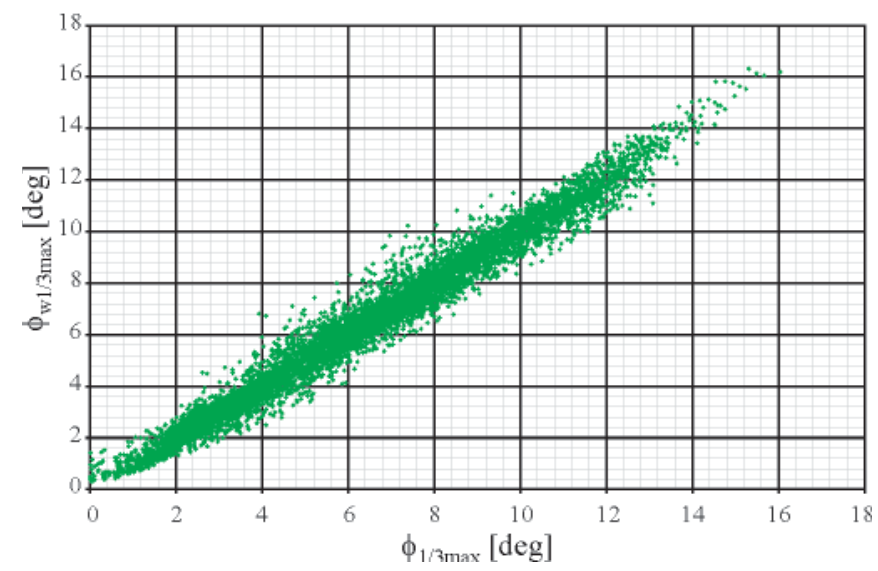

Fig. 7. Comparison of approximation accuracy relative to model values: $\phi_{w / 3 \max }$ - model value of roll motion; $\phi_{1 / 3 \max }$ - roll motion value approximated by using $E q$. (1)
Tab.2. Selected regression statistics

\begin{tabular}{|c|c|c|c|c|c|}
\hline & Eq.(1) & Eq. (2) & Eq. (3) & Eq.(4) & Eq.(5) \\
\hline $\begin{array}{c}\text { Pearson } \\
\text { regression } \\
\text { coefficient R }\end{array}$ & 0.976 & 0.891 & 0.93 & 0.98 & 0.91 \\
\hline $\begin{array}{c}\text { Standard } \\
\text { deviation of } \\
\text { error }\end{array}$ & $0.48^{\circ}$ & $1.03^{\circ}$ & $\begin{array}{c}4.25 \\
{[\%]}\end{array}$ & $\begin{array}{c}0.06 \\
\mathrm{~m} / \mathrm{s}^{2}\end{array}$ & $\begin{array}{c}0.3 \\
\mathrm{~m} / \mathrm{s}^{2}\end{array}$ \\
\hline
\end{tabular}

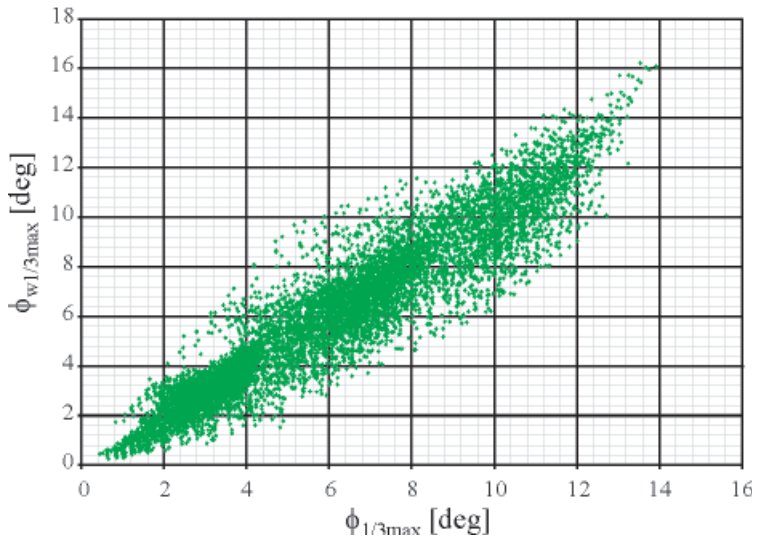

Fig. 8. Comparison of approximation accuracy relative to model values: $\phi_{\text {wl/3max }}$ - model value of roll motion; $\phi_{1 / 3 \max }$ - roll motion value approximated by using $E q$. (2)

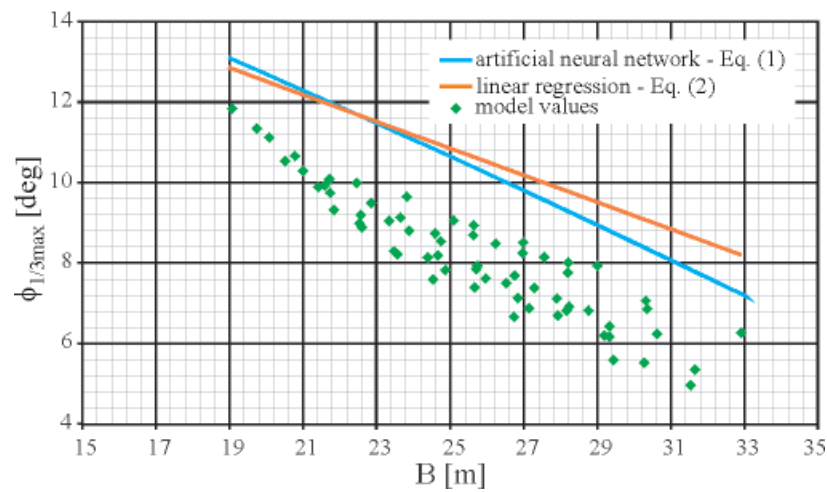

Fig. 9. Comparison of approximation accuracy relative to model values: $B=$ var, $C B=0.61, G M=0.8 m, H_{s}=3 \mathrm{~m}$

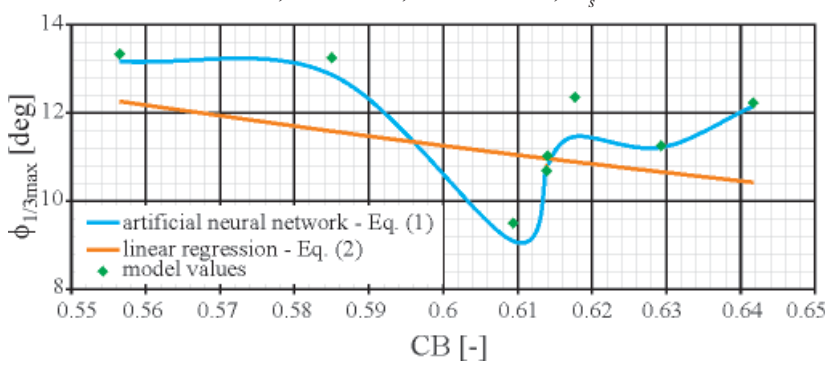

Fig. 10. Comparison of approximation accuracy relative to model values: $C B=$ var, $B=21.6 \mathrm{~m}, G M=1.0 \mathrm{~m}, H_{\mathrm{s}}=3 \mathrm{~m}$

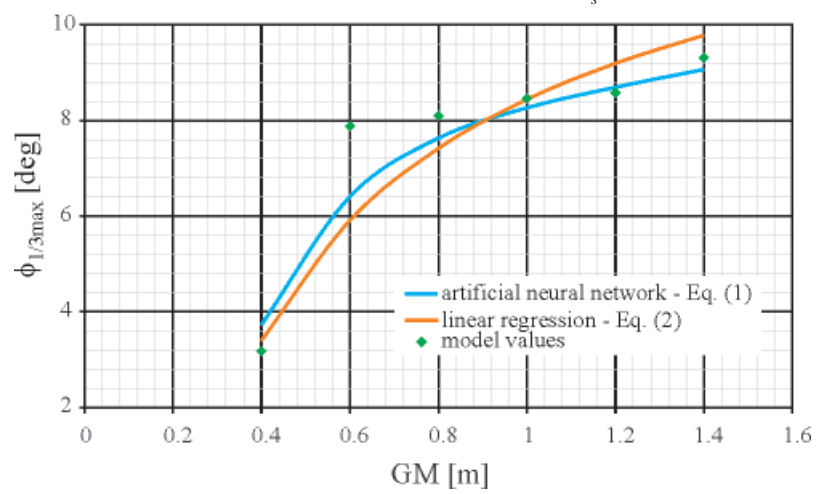

Fig. 11. Comparison of approximation accuracy relative to model values: $G M=$ var, $B=29.0 \mathrm{~m}, C B=0.63, H_{s}=3 \mathrm{~m}$ 


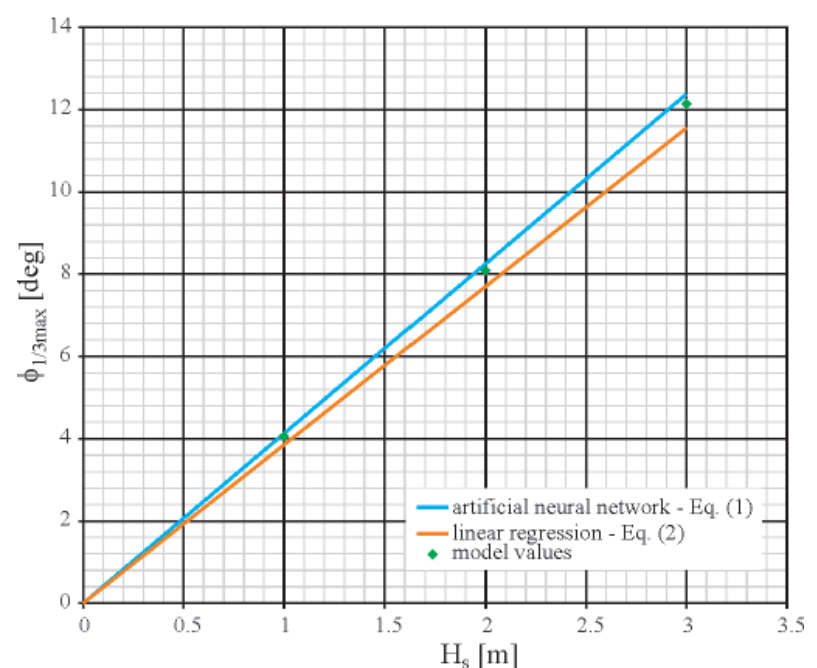

Fig. 12. Comparison of approximation accuracy relative to model values. $H_{S}=$ var, $B=21.42 \mathrm{~m}, C B=0.56, G M=0.8 \mathrm{~m}$

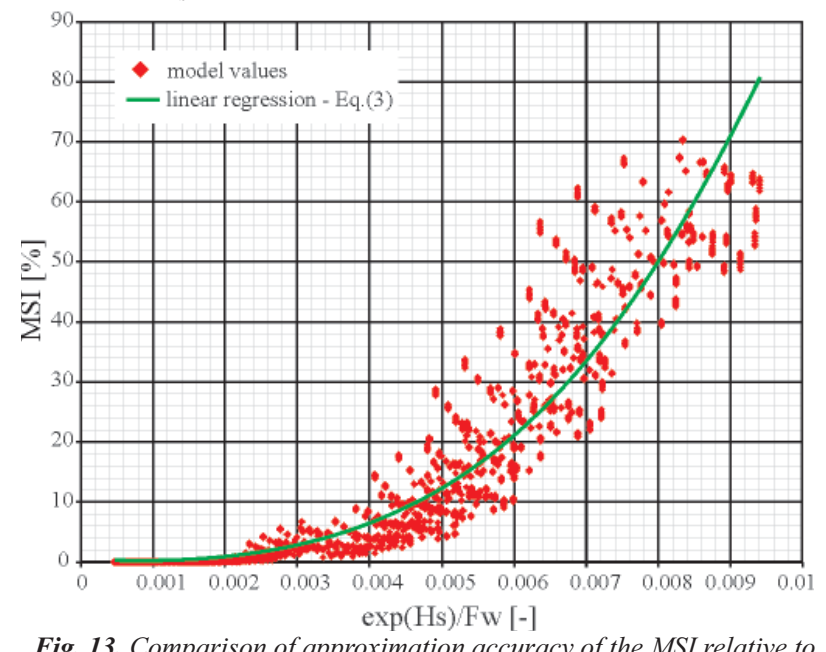

Fig. 13. Comparison of approximation accuracy of the MSI relative to model values

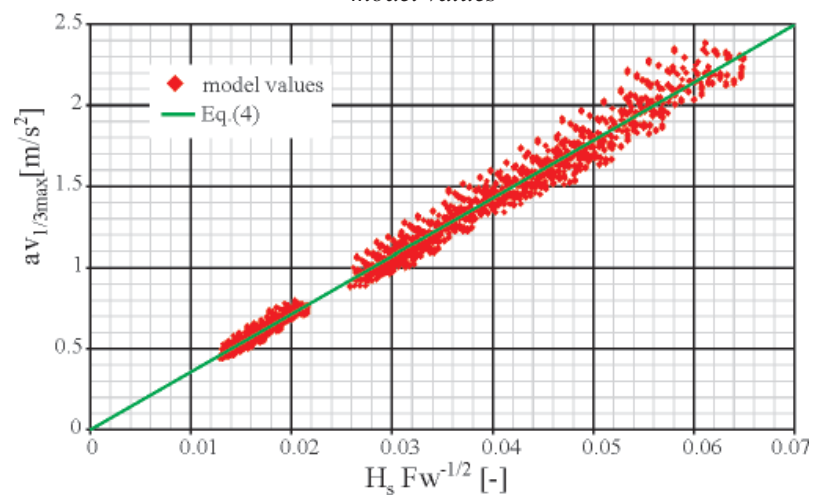

Fig. 14. Comparison of approximation accuracy of vertical accelerations relative to model values

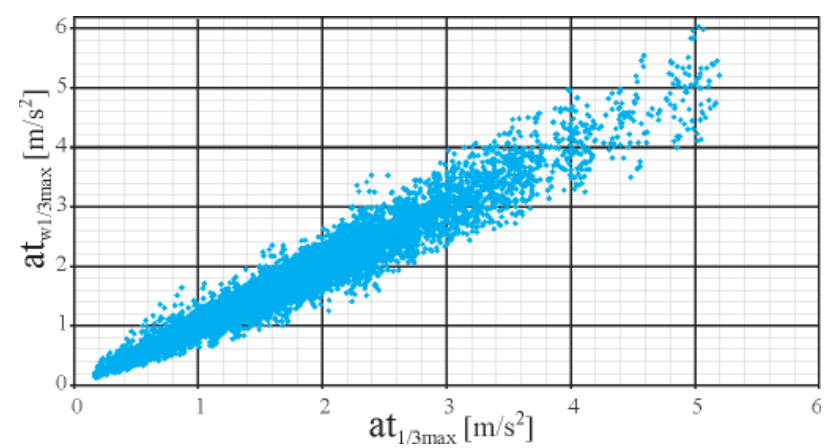

Fig. 15. Comparison of approximation accuracy of lateral accelerations relative to model values: at ${ }_{w 1 / 3 \max }$ - model value of significant amplitudes of lateral accelerations, at $t_{1 / 3 \max }-$ value of significant amplitudes of lateral accelerations, approximated by means of Eq. (5)

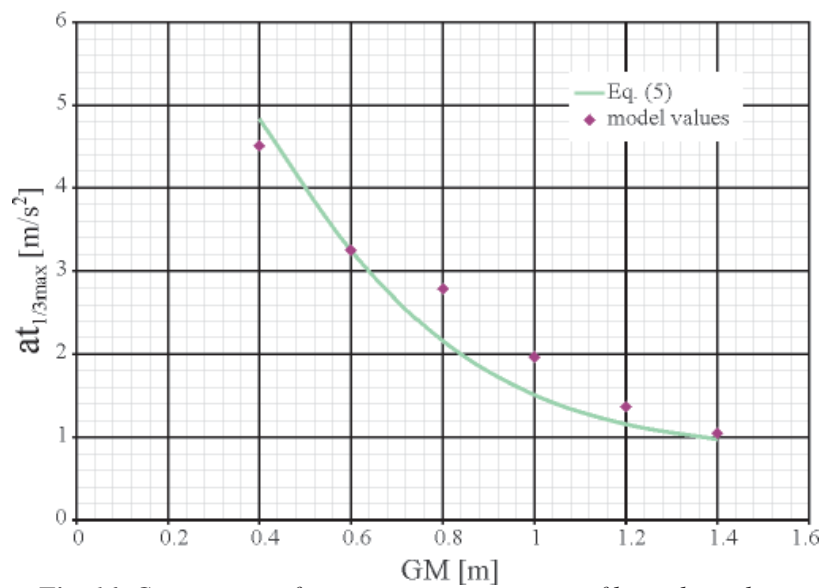

Fig. 16. Comparison of approximation accuracy of lateral accelerations relative to model values: $G M=$ var, $L w l / B=6.22, C M=0.97, H=3 \mathrm{~m}$

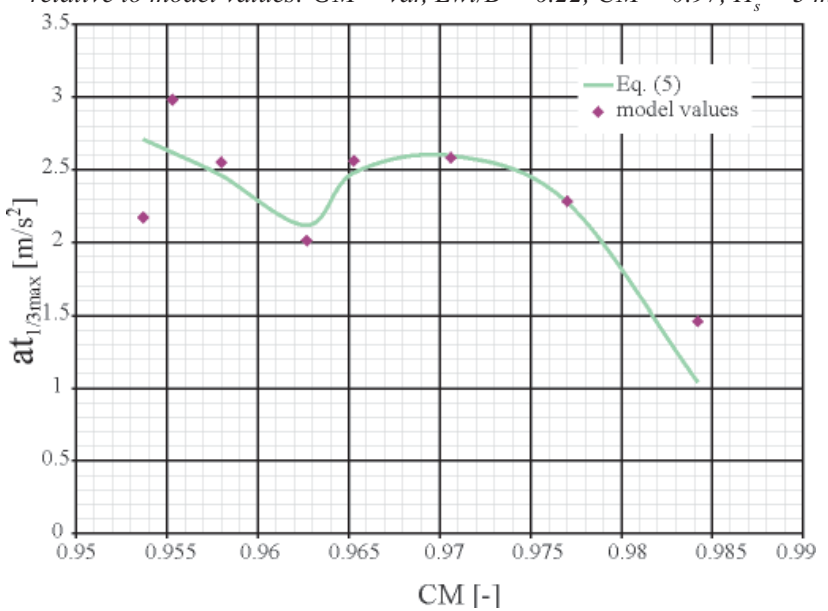

Fig. 17. Comparison of approximation accuracy of lateral accelerations relative to model values: $C M=$ var, $L w l / B=7.4, G M=0.8 \mathrm{~m}, \mathrm{H}=3 \mathrm{~m}$

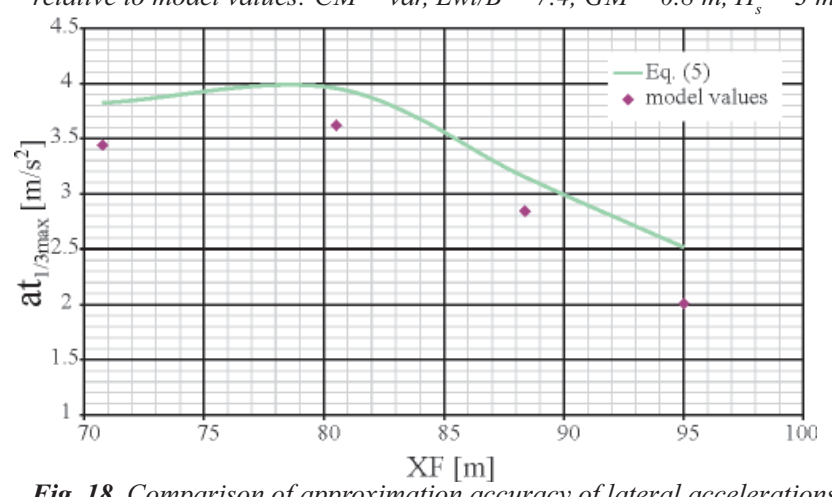

Fig. 18. Comparison of approximation accuracy of lateral accelerations relative to model values: $X F=$ var, $L w l / B=7.4, C M=0.95$, $G M=0.6 m, H_{s}=3 m$

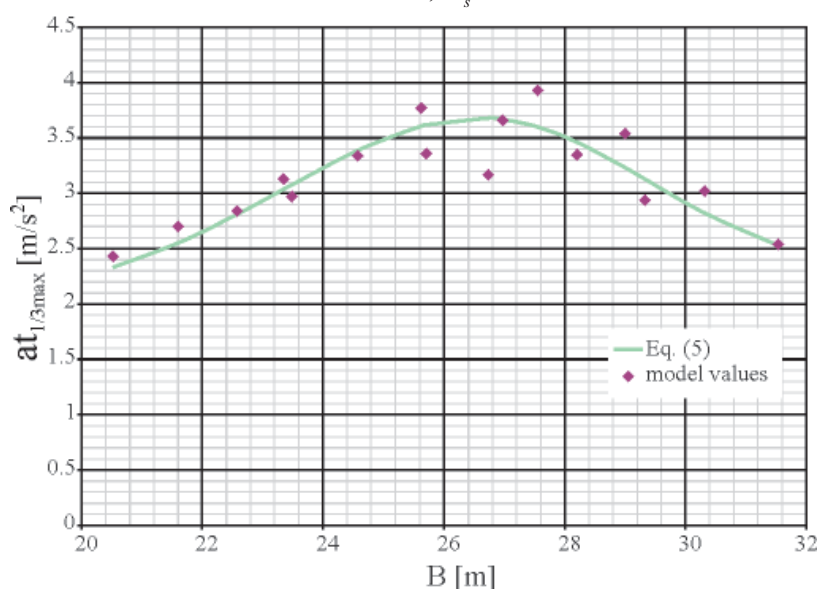

Fig. 19. Comparison of approximation accuracy of lateral accelerations relative to model values: $B=$ var, $\mathrm{Lwl} / B=7.0, C M=0.97$ $G M=0.8 m, H_{s}=3 m$ 


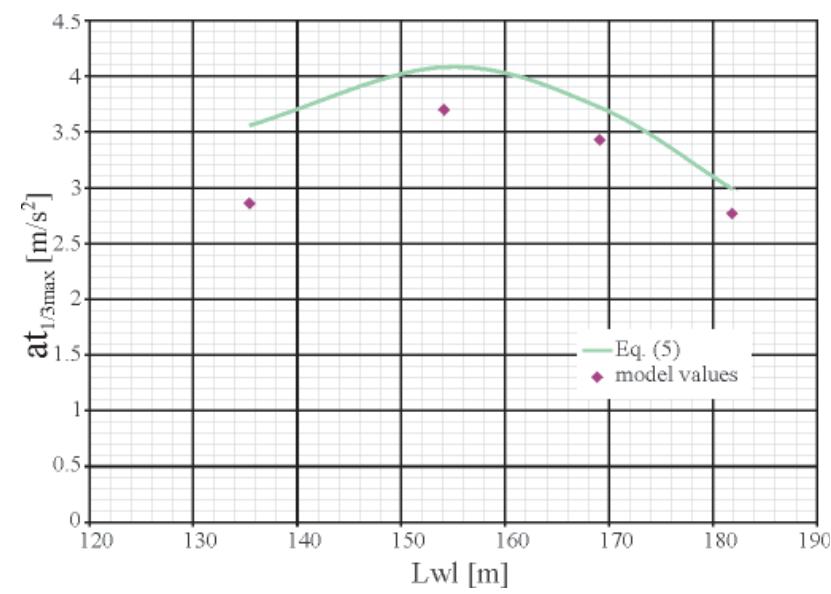

Fig. 20. Comparison of approximation accuracy of lateral accelerations relative to model values: $L w l=v a r, L w l / B=6.6, C M=0.95, G M=0.6 \mathrm{~m}$, $H_{s}=3 m$

\section{RANGE OF APPLICATIONS AND LIMITATIONS OF THE ELABORATED RELATIONS}

The elaborated design guidelines may find application to design calculations of the passenger-car ferries:

- of parameters and hull forms consistent with the ranges used for the model variants,

- intended to operate in the assumed service conditions.

With taking into account the first group of the above mentioned limitations, the relations (1), (2), (3), (4) and (5) can be especially used for design calculations of passengetcar ferries of the following dimensions and parameters:
1. $\mathrm{LBd}=19000 \div 46000 \mathrm{~m}^{3}$
2. $\mathrm{L} / \mathrm{B}=5.8 \div 8.2$
3. $\mathrm{B} / \mathrm{d}=3 \div 4.5$
4. $\mathrm{CB}=0.56 \div 0.64$
5. $\mathrm{CWL}=0.75 \div 0.85$
6. $\mathrm{LWL}=124 \div 258 \mathrm{~m}$
7. $\mathrm{B}=19 \div 33 \mathrm{~m}$
8. $\mathrm{CM}=0.95 \div 0.98$
9. $\mathrm{XF}=55.2 \div 117.6 \mathrm{~m}$
10. $\mathrm{FW}=2100 \div 6000 \mathrm{~m}^{2}$.

\section{CONCLUSIONS}

- The elaborated design guidelines can be applied to preliminary ship design as tar get functions or technical limitations.
- If recommended limit values of the presented sea-keeping qualities are known limit values of ship design parameters can be determined. For instance, to keep MSI value below $20 \%$ is recommended according to [6]And, by making use of Eq. (3) the limit area of waterplane can be calculated depending on the significant wave height Hs.

- The elaborated relations are characterized by diferent levels of complexity and approximation accuracy Eqs. (1) and (5) are of the most complex structure (they were elaborated with the use of artificial neural networks), but simultaneously they show the highest approximation accuracy.

- All the relations are based on the data available in the preliminary stage of ship design process.

\section{BIBLIOGRAPHY}

1. Dudziak J.: Ship theory (in Polish). Fundacja Promocji POiGM (Ship Industry \& Maritime Economy Promotion Foundation), Gdańsk 2008

2. Journée J.M.J.: Verification and Validation of Ship Motions Program SEAWAY. Report1213a, Delft University of Technology, The Netherlands, 2001

3. Frank W.: Oscillation of Cylinders in or below the Free Surface of Deep Fluids. Technical Report 2375, Naval Ship Research and Development Centre, Washington DC, U.S.A., 1967

4. BAL TIC GATEWAY Report: Future trends in the design of ro-ro and ro-pax vessels operating in the southern Baltic., Sea Highways Ltd, 2005

5. Kobyliński L.: Goal-based stability standards. Proceedings of the 9th International Ship Stability Workshop, Germanischer Lloyd Operating 24/7, Hamburg 2007

6. Riola J.M., M.Garcia de Arboleya: Habitability and personal space in sea-keeping behaviour. Journal of Maritime Research, Vol III, No 1, 2006

7. Schneekluth H., Bertram V.: Ship Design for Efficiency and Economy. Butterworth-Heinemann, 1998

8. Szozda Z.: A concept of Ship Stability Criteria Based on Cargo Shift Caused by Rolling due to Gust. Zeszyty Naukowe (Scientific Bulletin) No. 2(74), Szczecin Maritime University, Szczecin 2004

CONTACT WITH THE AUTHOR

Tomasz Cepowski, Assoc. Prof. Institute of Marine Navigation, Maritime University of Szczecin Wały Chrobrego 1/2

70-500 Szczecin, POLAND e-mail: cepowski@am.szczecin.pl 